\title{
Street construction for environmental processes
}

\author{
B. K. Ferguson \\ College of Environment and Design, University of Georgia, Athens, USA
}

\begin{abstract}
In urban areas where natural environmental processes are allowed to occur, they contribute to air and water quality, stable water supply, flood moderation, biodiversity, and reduced demand on energy producers and sewer collection systems. Urban landscape technologies developed in recent years make a radical combination of environmental and human functions possible in the streets of dense urban districts. This paper reviews their construction, roles, and performance, and illustrates their application in urban design. Beneath trafficked surfaces, structural soils or deck-like bridging structures maintain viable tree rooting space, enabling street trees to grow to the size necessary to provide effective shade, cooling, biodiversity, and air quality. Permeable pavements of concrete, open-jointed blocks, and other materials open vehicular and pedestrian surfaces to air and water, allowing urban soils to absorb rainwater, reduce runoff, restore water quality, recharge regional aquifers, and activate tree rooting zones. Where urban space permits, open rain gardens use soil to combine water restoration and growth of living things. Contemporary urban design analyses complete the realization of a street's multiple roles by identifying and integrating spaces for these technologies in the midst of dense urban construction. Monitoring has confirmed environmental performance, while industry innovations and standards continue to evolve. Participation in natural processes is a relatively new concept for cities, which in the past have been considered sacrifices of local environment for human welfare. In the kind of street that can be constructed today, there need not be antagonism between environmental processes and human welfare.
\end{abstract}

Keywords: construction, design, environment, landscape, streets. 


\section{Introduction}

Environmental processes have the same potential in city streets as they do anywhere else. Wherever a city is placed on the surface on the earth, underlying soils and aquifers are given by geography; sun, wind, rain, and living things play on them. Urban design and construction permit to greater or lesser degrees these processes to grow into the healthy open systems of which they are capable; but they are always there.

Urban environmental conflicts of the past have been recognized for decades. Impervious urban construction seals a landscape, prohibiting the rooting of living things and annihilating interchange of air and water. Living biomass is small; species are few. Unshaded construction materials absorb solar radiant heat, raising temperatures into a 'heat island' where excess energy is consumed for building air-conditioning. During storms excess runoff floods urban streams, erodes their channels, and pollutes them with oil and bacteria. Afterwards ground water is low because water was flushed out of the watershed when it was available; stream base flow and the aquatic habitat it supports are lost; some communities are left with local water shortages. With these systems, urban construction was considered sacrificial of natural processes. Cities and environment were believed to be dichotomous and antagonistic. The technologies of the time gave no choice; mankind did not know how to do otherwise.

Street-level construction is a particularly powerful regulator of urban environmental flows. In North American cities, pavements typically occupy two thirds of the built-surface area. They produce most of a city's excess runoff because they control a large rainwater catchment area. They largely control urban stormwater quality because pollutants from dumpsters, animals, and vehicles originate on them.

Urban landscape technologies developed in recent years make a new combination of environmental and human functions possible in the streets of dense urban districts. This paper reviews the technologies' roles, construction, and performance, and illustrates their application in urban design.

\section{Trees and technologies for tree rooting}

Among living species potentially growing in densely built-up areas, canopy trees are the physically dominant form. Despite their overall bulk they fit physically into urban streets, because only the slender trunk, which is mostly nonliving support wood, is at human activity level. The active living parts are the wide canopy above and the equally wide roots below.

Full-grown trees are functionally powerful. Their large canopy leaf area absorbs sunlight, houses insects and other living things, absorbs carbon dioxide from the air, emits oxygen, and removes particulates and other urban air pollutants. Trees bring biodiversity, colour, and structure to urban space. They shade the ground surface, lowering the temperature, conserving energy in nearby 
air-conditioned buildings, and reducing the pollutants generated by regional power plants (Wilson [1]).

For trees to grow to the full size necessary to provide their potential effects, they must be provided with rooting space proportional to the area of the tree canopy at maturity (Trowbridge and Bassuk [2]). The soil volume is the reservoir from which roots draw water to the canopy for transpiration; the capacity of the reservoir must be adequate for the canopy's total leaf area. Today it is possible to maintain viable rooting space beneath a city's trafficked surfaces using either compactive 'structural soil' mixtures, or bridging of pavement over uncompacted soil.

Structural soil is a mixture of open-graded (single-size) aggregate and a controlled amount of soil, placed as a pavement's base course. Where the mixture is properly proportioned, the aggregate bears the compaction of pavement traffic, and transfers it by stone-to-stone contact to the earth, protecting the soil between aggregate particles from compaction (Grabosky et al. [3]). The soil between particles remains uncompacted and available for root growth. Research and experience have confirmed properly proportioned structural soil's ability to support both traffic on the ground plane and healthy rooting below. At least during the first several years after planting, tree growth is far better than that in conventional compacted urban soil. Research continues to examine its long-term performance, in providing an adequately large soil reservoir for tree growth to full size, and in avoiding or counteracting the heaving pressure of widening roots.

Bridging is the spanning of a traffic-bearing surface over an uncompacted rooting soil. It differs from structural soil in that the soil volume is not diluted by structural aggregate particles; instead the bridge's framing carries the compactive traffic load to footings at the sides of the rooting soil, or through posts to the earth below. Bridging surfaces have been built of lumber and precast concrete. At least one company now manufactures a modular plastic cell for this purpose, in which posts support a frame where a pavement surface can be placed, and soil can be placed in the cell between the posts. In all bridging structures the soil is selected and managed only for its horticultural rooting value; between structural supports it remains uncompacted (Urban [4]). A structural bridge must always be built adequate to support its load of pedestrian or vehicular traffic.

Monitoring and experience have confirmed that both structural soil and bridging produce much better tree growth than that in compacted urban soil; an initial comparison of relative tree growth in the two approaches may favour the bridging approach (Smiley et al. [5]). Installations of both approaches must be designed and installed correctly. The soil must be uncompacted and adequately drained and irrigated. Tree species should be selected to fit the soil conditions they will be given, in terms of $\mathrm{pH}$, salt, and moisture regime.

\section{Permeable surfaces}

Permeable surfaces open the urban subsurface to exchange of air and water, allowing pavement base structures and soils to absorb stormwater, reduce runoff, 
reduce combined-sewer overflows, restore water quality, and recharge aquifers. Their aeration and irrigation contribute to the viability of rooting soil for living root tissue. Permeable pavements for vehicular and pedestrian surfaces have been developed in several materials; pervious concrete and open-jointed blocks are two important types which are reviewed here (Ferguson [6]).

Pervious concrete is chemically identical to conventional dense concrete, but it is made with open-graded (single-size) aggregate, which creates a network of voids in the concrete structure. Pervious concrete's quality control requirements to produce a permeable and durable structure are exacting. Experience and research have established, and are continuing to upgrade, important standards for installation and testing (ACI [7]). A mixture containing strictly single-sized aggregate can produce compressive strength sufficient for many applications with low and medium traffic levels, together with very high permeability. There is currently a trend toward mixes with controlled additions of sand, sacrificing excess permeability while importantly augmenting strength and durability. Designers, suppliers and installers must continue to be made aware of evolving industry standards, and their importance in controlling the quality of the product.

Open-jointed paving blocks are solid units shaped to leave open spaces in the joints; the open spaces are filled with highly permeable aggregate. The blocks and joints form a composite 'segmental' pavement that can infiltrate water while bearing traffic loads through the structure (Smith [8]). The blocks are manufactured of concrete or clay in controlled factory conditions. Worldwide experience and research have shaped industry standards that assure strong and highly permeable pavements. On-site quality control is not as demanding as that of pervious concrete, because there is no mixing or curing to be overseen.

Both pervious concrete and open-jointed block have been installed on slowly permeable clay soils, in freezing winter climates, and under the traffic of heavy vehicles; structural and hydrologic design procedures to address such conditions have been established. Monitoring has confirmed their environmental performance (Ferguson [9]). Surfaces that are properly designed, installed and maintained can absorb high rates of natural rainfall. Water that enters the pavement is treated and detained within the structure; excess water beyond what the soil can absorb discharges out a drainage pipe at a controlled rate. With permeable surfaces, in a single urban space, there can be a living tree canopy above, a living rooting zone below, absorption and treatment of stormwater through the surface, and the traffic of a busy city across the ground plane.

\section{Rain gardens}

Where urban space permits, open rain gardens use a layer of permeable soil to combine water restoration with plant growth. Rain gardens are sometimes called bioretention or bioinfiltration; the name 'rain garden' is preferred in this paper because it implies the multiple roles that are necessary for environmental processes in urban areas: collection of rainwater, support of living plants, and arrangement for human accommodation. Rain gardens receive excess stormwater from adjacent surfaces, store it, infiltrate it, treat it, return it to the soil, transpire 
it through the leaves of living plants, and discharge any excess at a controlled rate. Because they incorporate small shrubs and ground-level plants, in densely built-up areas they can be placed only in detailed pockets of space where they are out of the way of intense human activities. To be reliably permeable, the soil is given a high proportion of sand; and to remove dissolved pollutants there is also a certain amount of high-CEC clay, silt, or composted organic material. Plant species are selected for tolerance of recurrent wet conditions, and their addition of colour to street spaces.

Monitoring has confirmed rain gardens' environmental performance, while industry innovations and standards continue to evolve (Davis et al. [10]). Rain gardens reduce runoff volumes and rates by storage, infiltration, and evapotranspiration. They capture and degrade water pollutants by filtration and soil biochemistry. They reduce the temperature of runoff water. An adequate soil depth for plant rooting tends to be more than adequate for pollutant removal. Healthy plant life maintains soil permeability, supports microbiota that degrade water pollutants, and may uptake some pollutants directly. Research continues to address questions of design optimization such as soil composition and depth, ponding depth above the soil, and vegetation selection.

\section{Spatial allocation}

In a densely built-up street, tree stems and rain gardens must be spatially allocated, so as not to disrupt the organization of intense human activity. Permeable surfaces and special base materials, too, must be spatially allocated to be consistent with accessibility and traffic-load endurance.

Figure 1 illustrates the general spatial relationships between a street's human activities and potential environmental processes. Human activities occupy and
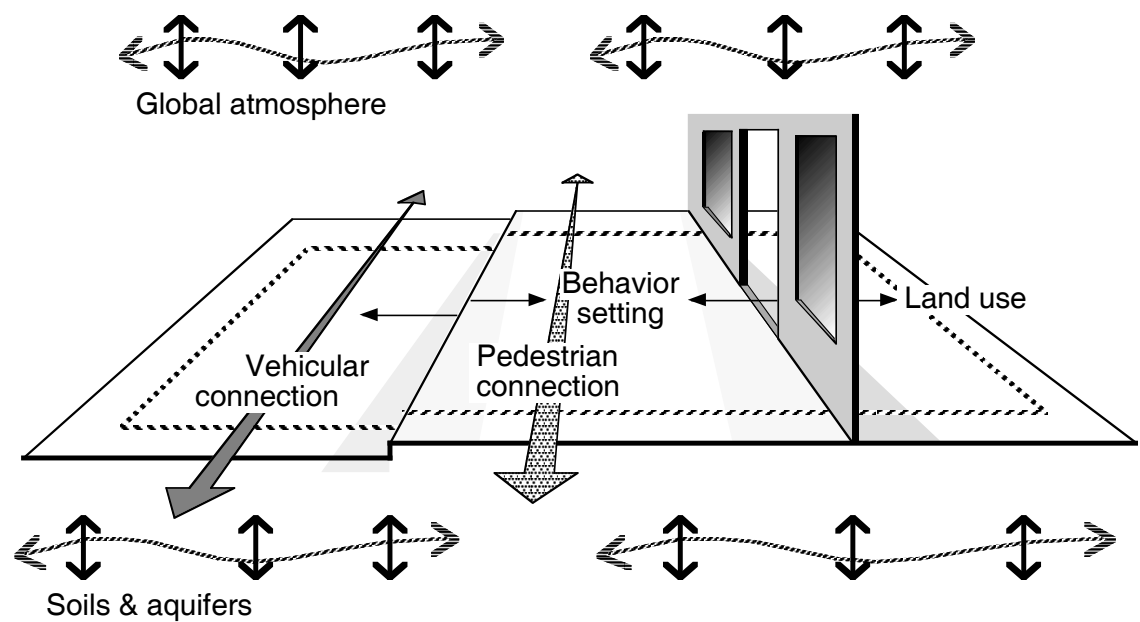

Figure 1: Combination of functions in city streets (after Ferguson [11]). 
connect the ground plane: vehicular and pedestrian movement are oriented longitudinally; the pedestrian walkway is also an in-situ behaviour setting; pedestrian linkages connect to vehicular transportation on one side, and into buildings' activities on the other. In contrast, potential environmental processes connect vertically above to the global atmosphere and below to soils and aquifers. The problem of environmental activation of densely built-up streets is one of extending functions vertically, to open environmental processes to the air and sunlight above, and the soil below, without disrupting the vital human organization at the surface plane.

Contemporary urban design analyses articulate and integrate the spaces for constructions that make a full combination of human and environmental functions possible. For walkways, explicit spatial analysis has evolved in recent years. A contemporary formulation by Vanderslice et al. [12] is shown in the right half of Figure 2. It distinguishes the pedestrian through zone, which is clear for through movement, from the frontage zone where the building's activities merge with those of the outdoor street, and from the furnishings zone near the curb, where diverse provisions and connections are made as needed. The through zone requires consistently accessible surface materials. The furnishings zone supports multiple functional connections (transit stops, bike storage, access to parked cars), behaviour accommodations (spaces and seating) and, importantly for the subject of this paper, anything that establishes the street's overall culture, environment, and utility (tree stems, rain gardens, plantings, lighting, parking meters, art).

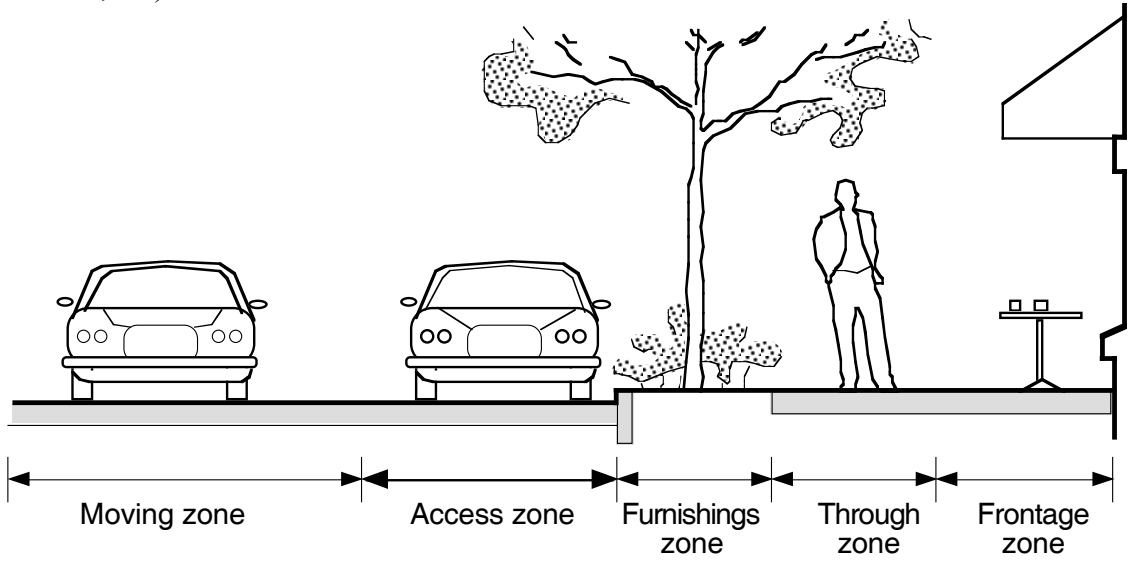

Figure 2: $\quad$ Specific spatial zones (partly after Vanderslice et al. [12]).

For vehicular ways, designers distinguish access zones from the moving lanes which were an exclusive emphasis in previous generations. In access zones vehicles of all kinds and purposes (transit, lorries, autos, buses) connect with the sidewalk and the buildings beyond. An access zone's traffic load is much lighter than that of a moving lane, so it has wider options for surfacing and base materials including permeable materials. 
The analytical recognition of a street's specific functional zones has guided their discreet mixture in new forms for specific appropriate contexts, such as residential combinations in Dutch 'woonerfs' or British 'home zones', 'traffic calming' to blend pedestrian and vehicular zones safely, and complete pedestrianization of some commercial streets.

\section{Illustration in practice}

A current project illustrates the application of these technologies and analyses in practice, and their implications for a type of urban design that integrates environmental processes (Landscape Architecture [13]). Eight blocks of South Grand Boulevard in St. Louis, Missouri, USA are being comprehensively reconfigured in both the walkways and the vehicular ways, to upgrade the district's safety, comfort, environmental performance, and contemporary urban value. The project was designed during 2009-2010 and is currently under construction.

The project's design diagrams and construction drawings clearly articulate roadways and walkways into functionally accommodating zones: pedestrian through zones, frontage zones, furnishing zones, parking lanes, loading zones, and moving lanes are all visible. With them, multiple functions are allocated and linked in interlocking arrangements along each block's length and across its width. The pedestrian through zone is surfaced with accessible pervious concrete. In the furnishings zone, tree stems alternate with pervious concrete pavements supporting bus shelters, seating, and other 'street furniture'. The entire furnishings zone is underlain by a continuous structural-soil trench and stormwater storage volume. Rain gardens occupy the sidewalk 'bulbouts' formed by pedestrian crosswalks. The parking lanes will be surfaced with open-jointed blocks if funding permits a further stage of construction. This is a spatially complex and functionally complete street, because an understanding of its multiple potential roles and the ways to make them real through spatial allocation and contemporary landscape technologies, was applied to it.

\section{Conclusion}

Urban technologies developed in recent years make a radical combination of environmental and human functions possible in dense urban districts. Research has monitored their performance; industry associations have established standards; experiences have been gained in diverse conditions. In cities where these technologies are applied, they sustain environmental flows that contribute to air and water quality, flood moderation, stable water supply, biodiversity, and reduced demand on energy producers and sewer collection systems. They support a kind of urban design in which human community and environmental processes thrive together, in the same dense urban place. Care is required in design, installation, and maintenance. Experience and knowledge are continuing to be built. 
Permeable surfaces and viable rooting soils are not distinct facilities added to the side of an unchanged urban district. They are new ways of building urban structures: they bring natural life-support functions into the hard surfaces constructed for direct human use. In the pockets where space permits, open rain gardens diversify urban species, enliven urban spaces, and lengthen the 'treatment train' through which excess stormwater is treated and restored.

Participation in natural processes is a relatively new concept for cities, which in the past have been considered sacrifices of local environment for human welfare. The building and rebuilding of cities need no longer be sacrificial of environmental processes. In the kind of street that can be constructed today, there need not be antagonism between nature and human welfare.

\section{References}

[1] Wilson, W. G., Constructed Climates: A Primer on Urban Environments, University of Chicago Press, Chicago, 2011.

[2] Trowbridge, P. J. \& Bassuk, N.L., Trees in the Urban Landscape: Site Assessment, Design and Installation, John Wiley \& Sons, Hoboken, 2004.

[3] Grabosky, J., Bassuk, N., \& Trowbridge, P., Structural Soils: A New Medium to Allow Trees to Grow in Pavement, revised edition, Landscape Architecture Technical Information Series (LATIS), American Society of Landscape Architects, Washington, 2002.

[4] Urban, J., Up By Roots, Healthy Soils and Trees in the Built Environment, International Society of Arboriculture, Champaign, Illinois, 2008.

[5] Smiley, E. T., Calfee, L., Fraedrich, B. R., and Smiley, E. J., Comparison of Structural and Noncompacted Soils for Trees Surrounded by Pavement, Arboriculture \& Urban Forestry vol 32, no 4, pages 164-169, 2006.

[6] Ferguson, B. K., Porous Pavements, Boca Raton: CRC Press, 2005.

[7] ACI, Pervious Concrete, Committee 522 Report, American Concrete Institute, Farmington Hills, Michigan, 2006.

[8] Smith, D. R., Permeable Interlocking Concrete Pavements: Selection, Design, Construction, Maintenance, 3rd edition, Interlocking Concrete Pavement Institute, Washington, 2002.

[9] Ferguson, B. K., Porous Pavements in North America: Experience and Importance, in NovaTech Conference Proceedings, Lyon, 2010.

[10] Davis, A. P., Hunt, W. F., Traver, R. G., \& Clar, M., Bioretention Technology: Overview of Current Practice and Future Needs, Journal of Environmental Engineering 135(3), pp. 109-117, 2009.

[11] Ferguson, B. K., A Street Is an Ecosystem: Conceptual Background and Implications for Practice and Teaching, European Council of Landscape Architecture Schools Conference Proceedings p. 857-863, Istanbul, 2010.

[12] Vanderslice, E., Brown, M., \& Senechal, J., Portland Pedestrian Design Guide, Pedestrian Transportation Program, Portland, Oregon, 1998.

[13] Landscape Architecture, South Grand Boulevard 'Great Streets Initiative', St. Louis, Landscape Architecture 101(10), p. 143, 2011. 